Lindley, T. T., A. R. Anderson, V. N. Mahale, T. S. Curl, W. E. Line, S. S. Lindstrom, and A. S. Bachmeier, 2016: Wildfire detection notifications for impact-based decision support services in Oklahoma using geostationary super rapid scan satellite imagery. J. Operational Meteor., 4 (14), 182-191, doi: http://dx.doi.org/10.15191/nwajom.2016.0414.

Journal of Operational Meteorology 3 is Short Contribution

\title{
Wildfire Detection Notifications for Impact-Based Decision Support Services in Oklahoma Using Geostationary Super Rapid Scan Satellite Imagery
}

\author{
T. TODD LINDLEY, AARON R. ANDERSON, VIVEK N. MAHALE, and THOMAS S. CURL \\ NOAA/National Weather Service, Norman, Oklahoma \\ WILLIAM E. LINE \\ Cooperative Institute for Mesoscale Meteorological Studies, University of Oklahoma, and NOAA/NWS/NCEP/Storm Prediction \\ Center, Norman, Oklahoma \\ SCOTT S. LINDSTROM and A. SCOTT BACHMEIER \\ Cooperative Institute for Meteorological Satellite Studies, University of Wisconsin, Madison, Wisconsin
}

(Manuscript received 24 May 2016; review completed 21 September 2016)

\begin{abstract}
On 18 February 2016 , wildfires burned $524.80 \mathrm{~km}^{2}(129682 \mathrm{ac})$ and damaged or destroyed 656 structures across Oklahoma. During this high-impact fire episode, meteorologists at the Norman, Oklahoma, National Weather Service Forecast Office leveraged experimental 1-min Geostationary Operational Environment Satellite-14 (GOES-14) imager super rapid scan operations for GOES-R (SRSOR) in concert with a text messaging-based notification tool within the Advanced Weather Interactive Processing System (AWIPS) to alert officials of remotely sensed wildfire hot spots. These notifications allowed Oklahoma Forestry Services and Oklahoma Department of Emergency Management to rapidly deploy local firefighting resources to the site of newly detected wildfire ignitions - in some instances before emergency 911 calls were received. This article will describe the Python application developed for use in AWIPS during real-time operations and will briefly illustrate SRSOR sampling of the fire outbreak, particularly the Buffalo Fire in northwestern Oklahoma. This use of SRSOR demonstrates the applicability of research-to-operations for GOES-R era capabilities in future impact-based decision support services.
\end{abstract}

\section{Introduction}

A high-impact wildfire episode burned $524.80 \mathrm{~km}^{2}$ (129 $682 \mathrm{ac}$ ) of prairie in Oklahoma and adjacent portions of Arkansas and Kansas on 18 February 2016. Although wildland fire was not pervasive across the region early in the day, adverse public impacts from wildfire were highly anticipated by afternoon. Extremely critical fire conditions were forecast [per Storm Prediction Center (SPC) fire weather outlooks ${ }^{1}$ ] due to environmental and meteorological patterns known to support southern Great Plains wildfire outbreaks (Lindley et al. 2014). Such infrequent but devastating

\footnotetext{
1 The relevant outlooks are available online at www.spc.noaa.gov/ products/fire_wx/2016/160218_0919_fwdy1_print.html.
}

wildfire episodes occur when anomalously warm and dry midlatitude cyclones bring intense downslope winds that interact with anthropogenic activities and infrastructure to ignite tens of wind-driven fires within the Plains' grass-dominated fuelscape. The most widespread and intense fire activity on 18 February 2016 occurred in Oklahoma (Fig. 1), where a total of 72 fires damaged or destroyed 656 homes, businesses, and outbuildings, and injured one firefighter.

As wildfires ignited across Oklahoma, the National Oceanic and Atmospheric Administration's (NOAA) Geostationary Operational Environmental Satellite-14 (GOES-14) was operating in an experimental rapid scan mode. This GOES-14 scanning strategy, known as the super rapid scan operations for GOES-R (SRSOR), emulates future capabilities to be

Corresponding author address: T. T. Lindley, 120 David L. Boren Blvd., Norman, OK 73072

E-mail: todd.lindley@noaa.gov 


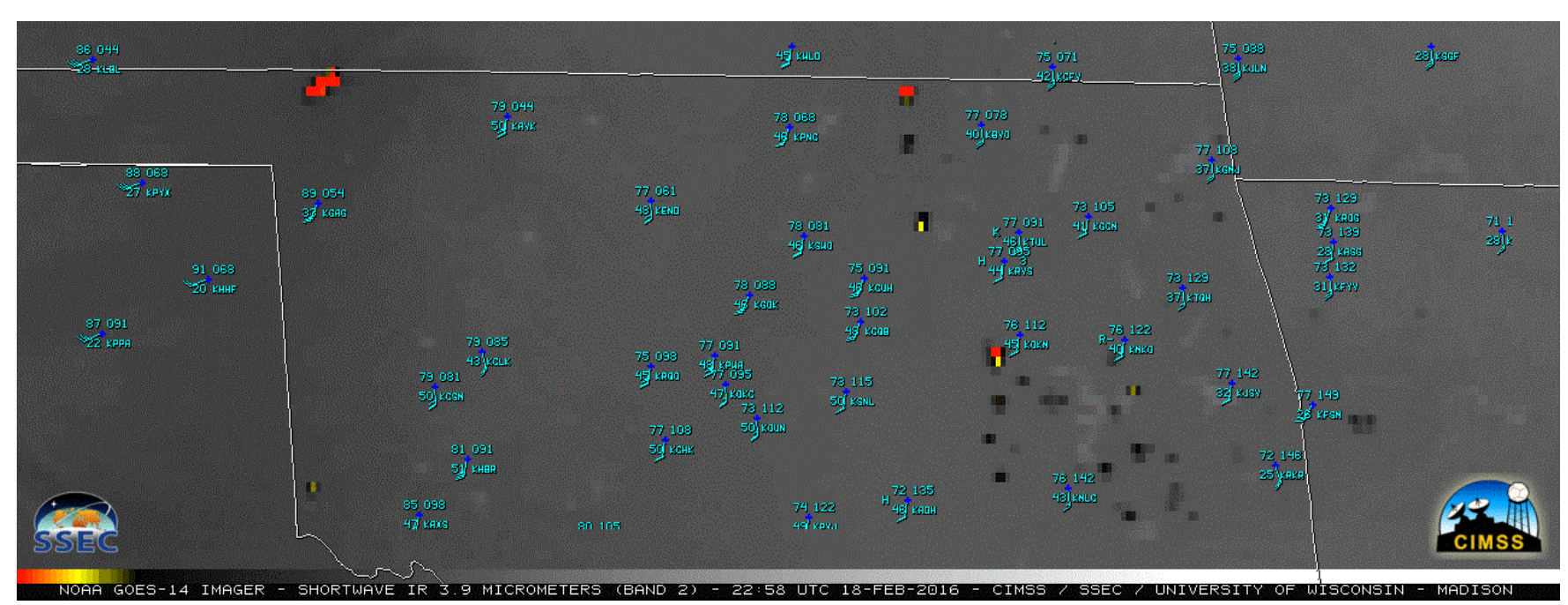

Figure 1. NOAA GOES-14 shortwave IR $(3.9 \mu \mathrm{m})$ imagery showing numerous wildfires in Oklahoma at 2258 UTC 18 February 2016. Warm brightness temperatures associated with fires are highlighted by black to yellow to red color enhancement, with red being the hottest. Click image for an external version; this applies to all figures hereafter.

deployed with the next generation GOES series $R / S / T$ instruments. SRSOR provides special 1-min datasets for algorithm developers, research partners, and forecasters who are working towards developing and implementing the next generation of GOES data into National Weather Service (NWS) operations. The GOES-14 Imager provided SRSOR data from 1 to 25 February and 18 April to 15 May 2016 with varied coverage area depending on expected weather. On 18 February, the University of Oklahoma Cooperative Institute for Mesoscale Meteorological Studies (OU/ CIMMS) and NOAA/SPC satellite liaison and Cooperative Institute for Research in the Atmosphere (CIRA) scientists determined that the SRSOR sector would be centered over the southern Great Plains to support fire weather operations. Forecasters and information technologists at the NWS Forecast Office in Norman, Oklahoma (WFO Norman), leveraged the availability of 1-min GOES-14 infrared (IR) imagery to detect wildfires and to provide near real-time notifications to emergency officials of remotely sensed wildfire ignitions. When forecasters identified wildfire hot spots, they generated Short Message Service (SMS) text messages using an innovative tool developed during live operations within the Advanced Weather Interactive Processing System (AWIPS). As reported by Oklahoma Forestry Services (OFS), these notifications "enabled rapid response that aided in keeping [some] fires small...thus reducing threat to life and property" (D. Daily 2016, personal communication).

This manuscript will briefly summarize the GOES14 SRSOR and its use in the operational environment to detect wildland fires. The AWIPS Python application developed to provide wildfire detection notifications to OFS and Oklahoma Department of Emergency Management (ODEM) will be documented. Further, SRSOR sampling of the $69.93 \mathrm{~km}^{2}$ (17 $280 \mathrm{ac)} \mathrm{Buf-}$ falo Fire will be described and compared to data from GOES-13/-15 to illustrate the utility of high-temporal resolution sampling of wildland fires. Most importantly, the use of SRSOR documented here will demonstrate how meteorological remote sensing can be utilized for tactical wildland firefighting support, as well as provide a glimpse of future applications of GOES-R era capabilities in impact-based decision support services (IDSS; NOAA 2013).

\section{GOES-14 SRSOR}

The first in a series of next-generation geostationary weather satellites that will provide coverage for the Western Hemisphere, GOES-R, is scheduled for launch in November 2016. GOES-R will introduce significant technological advancements for observing Earth's atmosphere and surface. Among these advancements will be the Advanced Baseline Imager (ABI). In addition to four times the spatial resolution (current GOES visible and IR resolution of 1 to $4 \mathrm{~km}$, respectively, compared to GOES-R visible and IR resolution of 0.5 to $2 \mathrm{~km}$ ) and three times more spectral bands, the ABI will provide up to five times the temporal resolution with 5-min full-disk GOES-R coverage versus the current GOES imager's $25 \mathrm{~min}$ (Schmit et al. 2005). 
Although not capable of the improved spatial or spectral attributes of the ABI, the GOES-14 imager was operated by NOAA in SRSOR mode during several multi-week periods spanning late 2012 through early 2016. These SRSOR windows have demonstrated the high-temporal resolution sampling capability of the GOES-R ABI when operating in mode 3, known as "flex mode," by providing 1-min imagery. The SRSOR data have been utilized in algorithm development, in various NWS field offices and national centers, and in operational support of experiments including those in the NWS's Operations Proving Ground and Hazardous Weather Testbed. Experimental use of SRSOR and the operational benefits of hightemporal resolution satellite imagery is well documented for numerous phenomena including fog and low stratus, convective storms, wildland fire and smoke, and tropical cyclones (Schmit et al. 2013, 2015; Line and Calhoun 2014; Gravelle et al. 2016; Line et al. 2016). Relating specifically to wildfires, past GOES-14 SRSOR sampling of the California Rim Fire on 19-22 August 2013 (Peterson et al. 2015) demonstrated that GOES-R ABI-like time resolutions allow sensing of rapid changes in fire characteristics (Schmit et al. 2015; Gravelle et al. 2016).

\section{AWIPS application and dissemination}

On 17 February 2016, WFO Norman was notified through the OU/CIMMS and NOAA/SPC satellite liaison that the SRSOR sector would cover the central and southern Great Plains on 18 February. Centered over $36^{\circ} \mathrm{N}, 101^{\circ} \mathrm{W}$, the SRSOR sector was wellpositioned over the extremely critical fire weather outlook area (Fig. 2). Upon notification, WFO Norman's information technology officer (ITO) and satellite meteorologist worked with the satellite liaison and CIRA research meteorologists at Colorado State University to begin ingestion and display of SRSOR shortwave IR (SWIR) imagery into AWIPS. The GOES SWIR band centered on $3.9 \mu \mathrm{m}$ is the primary channel on the current-generation GOES employed for sensing fire hot spots (Menzel and Prins 1996; Ruminski et al. 2003). Currently, automated fire detection algorithms, such as the Wildfire Automated Biomass Burning Algorithm product that utilizes GOES satellite imagery, are not available in AWIPS. Latency of SRSOR imagery in AWIPS was approximately 2-4 min. This reduced latency (compared to current GOES availability on the order of $10 \mathrm{~s}$ of $\mathrm{min}$ ) is crucial to

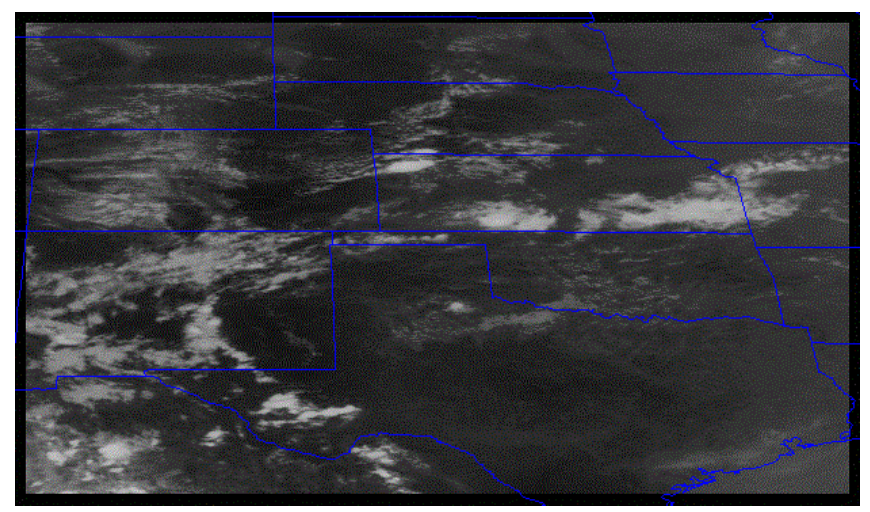

Figure 2. The GOES-14 SRSOR scanning sector employed on 18 February 2016.

integration of imagery in real-time operations (Gravelle et al. 2016).

With SRSOR SWIR imagery flowing in AWIPS, WFO Norman briefed OFS and ODEM on the potential for rapid detection of emerging wildfire hot spots during the anticipated extremely critical fire weather early on 18 February. Expectations were high that with the availability of 1-min GOES-14 SRSOR imagery, increased confidence in wildfire identification, and timely notifications of remotely sensed wildfires, could result in more rapid response and initial attack of firefighting efforts with improved ability to control and suppress new wildland fires. As a result of the early day meeting, OFS requested that WFO Norman provide real-time intelligence of newly detected ignitions to state watch duty officers.

After receiving the request for real-time fire intelligence by OFS, the WFO Norman ITO quickly developed a Python-based application that would allow forecasters to send the location of hot spots via text messages to a pre-determined list of cellular contacts-directly through AWIPS. Leveraging the availability of SRSOR data and the improved temporal resolution and latency, forecasters could quickly identify the latitude and longitude of hot spots using the Common AWIPS Visualization Environment (CAVE) points tool. Using the denoted CAVE point as manually positioned over the hot spot by a forecaster (Fig. 3), the Python-created text message contained a hazard/message type (i.e., wildfire), latitude, and longitude of the defined point, as well as additional weather information from the nearest Oklahoma Mesonet site such as temperature, relative humidity, wind direction, wind speed, and wind gusts. These text messages were then sent out through AWIPS via SMS email-to-text. In addition, forecaster remarks as well as 


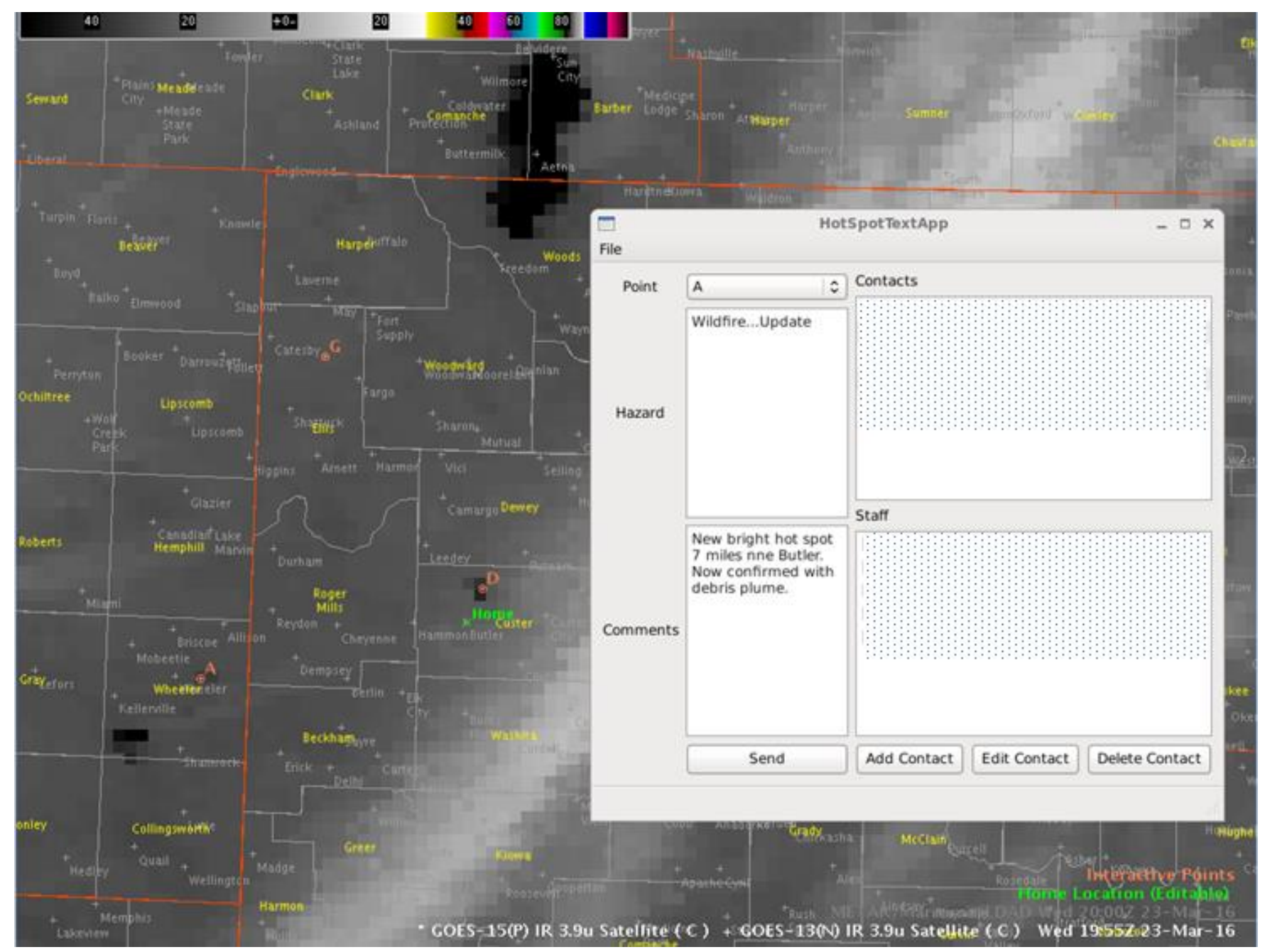

Figure 3. Screen capture of hot spot identification and forecaster input via GOES SWIR 3.9- $\mu$ m imagery within CAVE used for cellular text-based wildfire notifications. Contact information is obscured.

a link to the National Digital Forecast Database (NDFD) activity planner for temperature, wind speed and gust, relative humidity, and red flag threat index (Murdoch et al. 2012) were included with the text message (Fig. 4).

A total of eight wildfire notifications were transmitted by WFO Norman on 18 February 2016. Postevent feedback from OFS stated that these notifications were "key contributors to a measure of effectiveness in response to very aggressive and fast-paced fire activity" and that the dissemination of this information "enhanced situation awareness" and "permitted contact [with] a few departments in advance of 911 calls." It was additionally noted that "fire location often plays a role in resource allocation priority" and that text messages enabled a timely dispatch of resources and aided in prioritization of fires "with struc- tures and improvements at risk" (D. Daily 2016, personal communication).

\section{SRSOR analysis and IDSS during the Buffalo Fire}

During the 18 February 2016 fire outbreak, a very large and damaging wildfire, known as the Buffalo Fire, burned $69.93 \mathrm{~km}^{2}$ (17 $280 \mathrm{ac)}$ ) in Harper County of northwestern Oklahoma. A SWIR hot spot associated with the Buffalo Fire was initially sampled by SRSOR at 2045 UTC and available in CAVE at 2049 UTC. A text notification of the wildfire detection was transmitted by WFO Norman at 2053 UTC and contained a proximity weather observation from the Oklahoma Mesonet site near Buffalo, Oklahoma (14 km east-southeast of the fire), that showed a temperature of $305.15 \mathrm{~K}\left(32^{\circ} \mathrm{C}\right)$, southwest winds sustained at 12 


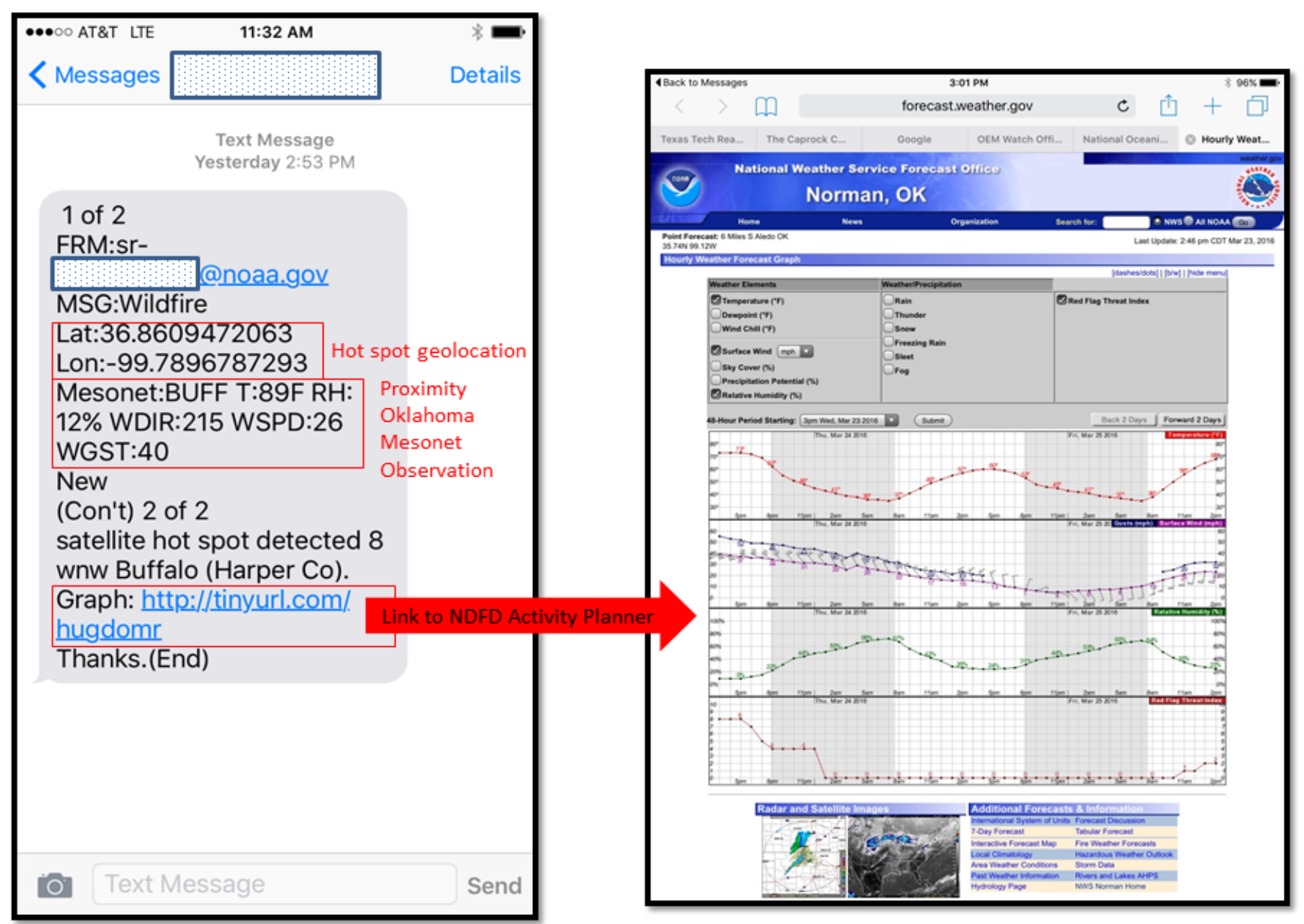

Figure 4. Example cellular text messaging output (left) of the wildfire notification with hot-spot geolocation, Oklahoma Mesonet proximity observation, and linked NDFD activity planner for selected fire weather parameters (right). Contact information is obscured.

$\mathrm{m} \mathrm{s}^{-1}$ (23 kt) gusting to $18 \mathrm{~m} \mathrm{~s}^{-1}(35 \mathrm{kt})$, and $12 \%$ relative humidity. The fire spread $21.7 \mathrm{~km}$ through grass-dominated fine fuels during its 3.5-h duration (average rate of spread $\sim 1.7 \mathrm{~m} \mathrm{~s}^{-1}$ ) and was wellsampled by SRSOR imagery (Fig. 5). This section will provide an in-depth discussion of SRSOR analysis and use of the AWIPS application in real-time IDSS for the Buffalo Fire.

Benefits of the improved temporal resolution obtained by GOES-14 SRSOR can be seen in plots of SWIR brightness temperature. The Buffalo Fire was sampled at two locations: the site of hot spot origination $\left(36: 51: 36^{\circ} \mathrm{N}, 99: 48: 27^{\circ} \mathrm{W}\right)$ and at a point immediately downwind (northeast) of the origin (36:54:44 $\left.{ }^{\circ} \mathrm{N}, 99: 43: 22^{\circ} \mathrm{W}\right)$ through which the fire front propagated (Figs. 6a-c). Notable changes in SWIR brightness temperature were observed on the 1min imagery, allowing for quick detection and subsequent notification of the hot spot to fire officials.
Initial detection of the Buffalo Fire was indicated by an increase from ambient background brightness temperatures between $305 \mathrm{~K}\left(31.9^{\circ} \mathrm{C}\right)$ and $310 \mathrm{~K}\left(36.9^{\circ} \mathrm{C}\right)$ prior to ignition to $327.5 \mathrm{~K}\left(54.4^{\circ} \mathrm{C}\right)$ at $2045 \mathrm{UTC}$. By 2048 UTC, brightness temperatures at the ignition site had met or exceeded the GOES-14 SWIR detectors' saturation temperature of $341.2 \mathrm{~K}\left(68.1^{\circ} \mathrm{C}\right)$. Note that with the launch of the GOES-R series, the SWIR saturation temperature will improve to be $>400 \mathrm{~K}$ $\left(126.9^{\circ} \mathrm{C}\right)(\mathrm{Schmit}$ et al. 2016). Rapid changes of up to $\pm 10 \mathrm{~K}\left( \pm 10^{\circ} \mathrm{C}\right)$ were then indicated as brightness temperatures gradually moderated back toward ambient background conditions by approximately 2220 UTC. Similar detail was observed at the downwind site, as an ambient brightness temperature of $307 \mathrm{~K}$ $\left(33.9^{\circ} \mathrm{C}\right)$ increased to $326 \mathrm{~K}\left(52.9^{\circ} \mathrm{C}\right)$ within a 6-min period in association with the fire front passage between 2115 and 2121 UTC. Increases in brightness temperature continued until sensor saturation was met at 2136 UTC. 


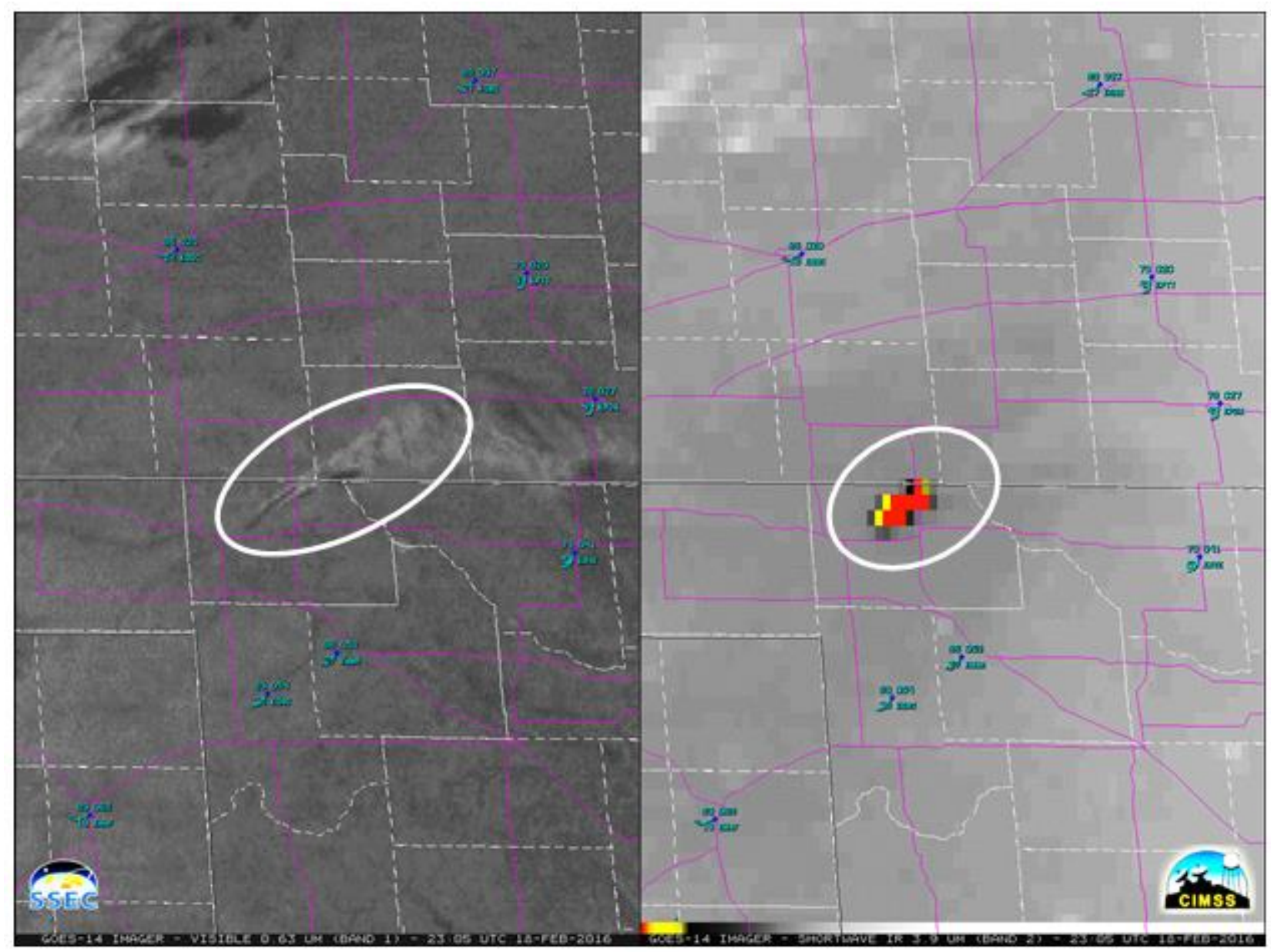

Figure 5. GOES-14 visible $(0.63 \mu \mathrm{m})$ imagery showing the Buffalo Fire smoke plume (left, circled) and corresponding SWIR $(3.9 \mu \mathrm{m})$ imagery showing the associated hot spot (right, circled) at 2305 UTC 18 February 2016. Warm IR brightness temperatures associated with the fire are highlighted by black to yellow to red color enhancement, with red being the hottest (right).

The rapid changes in behavior of the Buffalo Fire as observed on high temporal resolution imagery would not have been captured by scanning strategies of either the operational GOES-13 (operating in $\sim 5$ min RSO) or GOES-15 (operating in $\sim 15$-min routine operations). Figure 7 shows comparisons of GOES-15 routine operations, GOES-14 SRSOR, and GOES-13 RSO. In this instance, it appears that both GOES-13 and GOES-14 detected the fire at 2045 UTC. In fact, GOES-13 actually scanned the fire at 2050 UTC due to slower scanning capabilities, $\sim 5$ min after the 2045 UTC scan began at the North Pole. More importantly, the GOES-13 image was not available for forecasters to view in CAVE until 2057 UTC. GOES-14 SRSOR, however, actually scanned the fire at 2045 UTC while sampling a smaller coverage sector, and was available to view in CAVE at 2049 UTC. Also, there were no GOES-15 images available during a 30-min period be- tween 2030 and 2100 UTC due to satellite housekeeping activities. Therefore, through use of GOES-15 alone, initial fire detection would have not been possible until 2112 UTC when the 2100 UTC scan (that actually scanned the fire at 2106 UTC) was available in CAVE. Thus, SRSOR detection of an initial hot spot associated with the Buffalo Fire was available to forecasters 8 -min $(23-\mathrm{min})$ prior to availability from the operational GOES-13 (GOES15). Such improvements in temporal resolution and data latency are critical to the provision of IDSS for fast moving wildfires in fine fuels. Given the Buffalo Fire's $1.7-\mathrm{m} \mathrm{s}^{-1}$ average rate of spread, the delay in operationally available GOES-13 and GOES-15 imagery useful for identifying an initial hot spot compared to SRSOR represents a potential linear fire front advancement of $0.8-2.4 \mathrm{~km}$. Generally, as the head of a grassland wildfire advances, it also widens laterally 


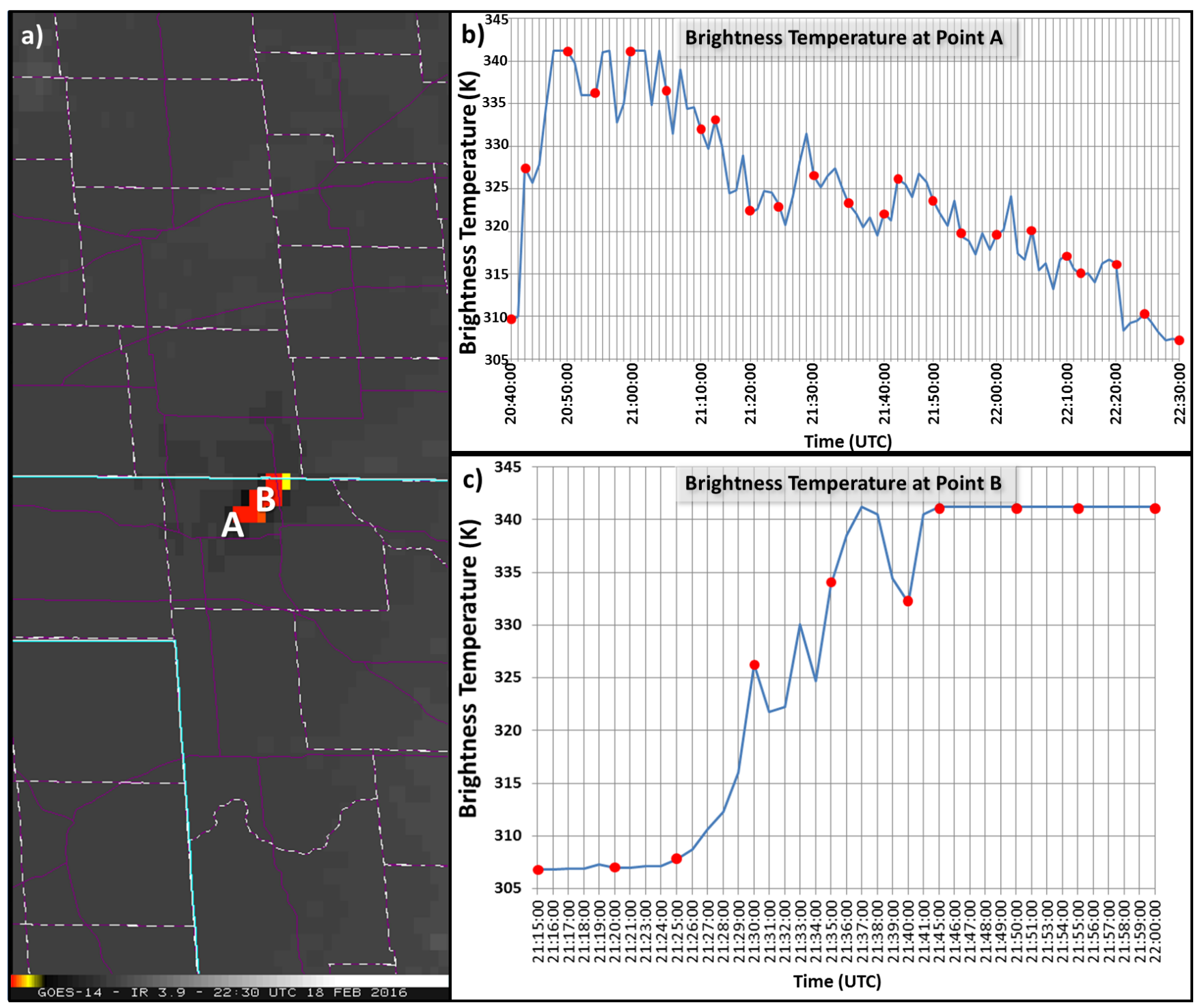

Figure 6. (a) GOES-14 SWIR brightness temperature at 2230 UTC and brightness temperature plots (b and c) using 1-min SRSOR data from two points: (A) the ignition point of the Buffalo Fire between 2040 and 2230 UTC 18 February 2016 in (b), and (B) a point downwind impacted by the passing fire front between 2115 and 2200 UTC 18 February 2016 in (c).

and the rate of spread increases (Cheney and Sullivan 2008). Therefore, effectiveness of initial suppression efforts in mitigating extreme fire behavior is time sensitive, and the 8-23-min advantage provided by SRSOR here has tactical value in providing actionable fire intelligence.

\section{Subsequent IDSS, feedback, and discussion}

Development of the AWIPS text message application and use of SRSOR to quickly detect and notify OFS/ODEM officials of wildfires proved to be an operational success in IDSS for WFO Norman during the fire outbreak on 18 February 2016. Although this application could have been developed independent of GOES-14 SRSOR, the tool served as a real-time solution to quickly and efficiently communicate information provided by the unique availability of experimental remote sensing data. The tool can be adapted for various uses within AWIPS and can be implemented at any NWS WFO.

Building upon the success of the 18 February 2016 wildfire notifications, ODEM developed a geographic information system (GIS)-based on-line situational awareness display used by multiple state and federal agencies to monitor wildfire incidents, resource allocation, and response across the state (Fig. 8). During a subsequent fire episode that impacted Oklahoma on 


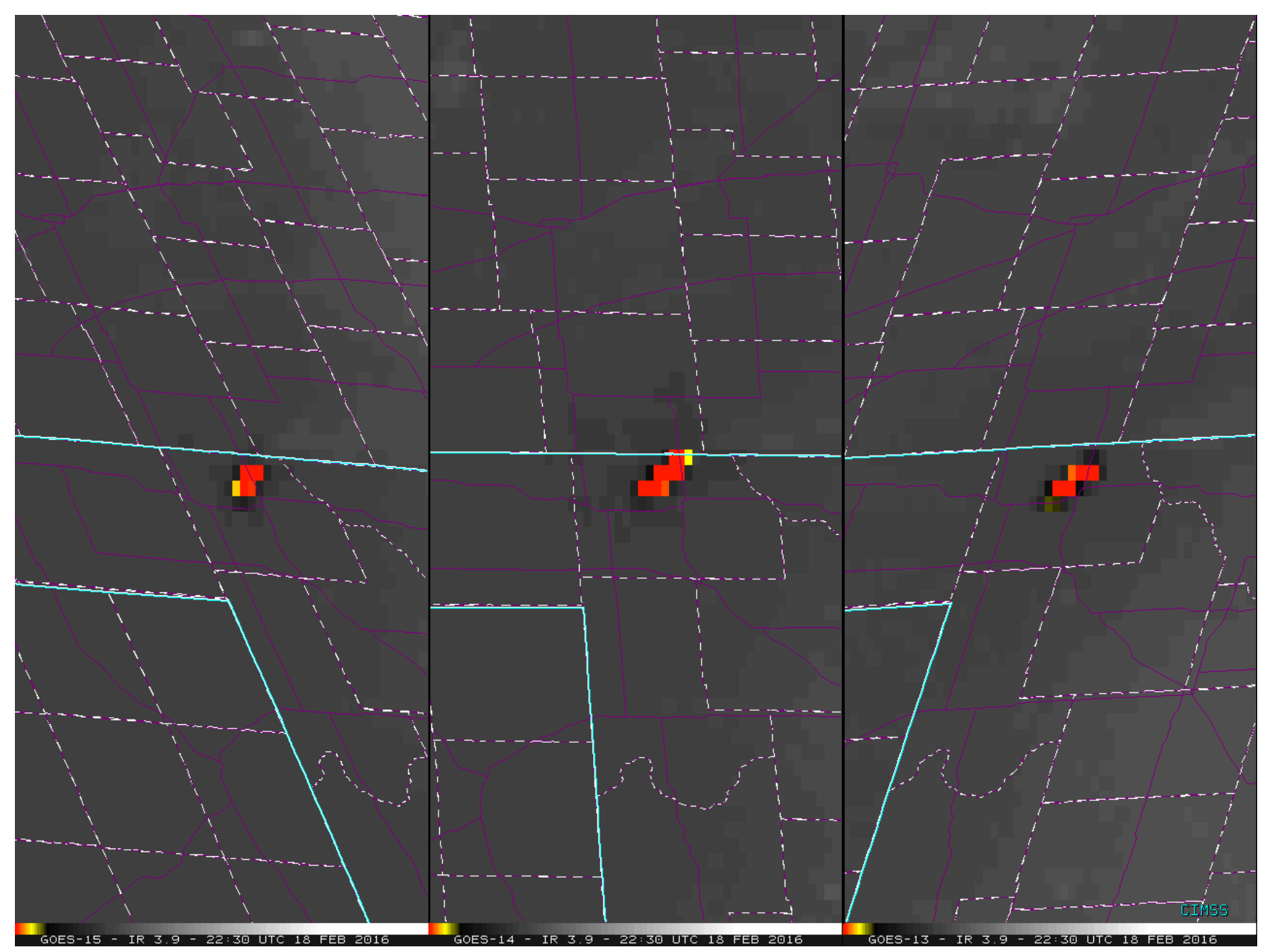

Figure 7. (a) GOES-15 (left), GOES-14 (center), and GOES-13 (right) 3.9- $\mu \mathrm{m}$ SWIR images covering the Buffalo Fire valid 2230 UTC 18 February 2016. Click image for an animation from 2030 to 2300 UTC 18 February 2016.

22-23 March 2016, NWS wildfire text notifications were combined with OFS and ODEM inputs for realtime monitoring of the wildland fire situation on the online GIS display. GOES-14 was unavailable at the time of this outbreak; however, the relatively lower temporal resolution GOES-13 5-min RSO data were used and still provided valuable information in the detection of wildland fires during the event. Timely wildfire text notifications and the development of these tools prompted by the previous availability of high temporal resolution GOES-14 SRSOR data during the February 2016 experimental window were noted by ODEM watch officers to have "saved them from having to call air support" in response to a fire near Okfuskee, Oklahoma (D. Piltz 2016, personal communication). Additionally, continued use of text notifications on 5 April 2016 prompted the following feedback from Major County Emergency Manager,
Tresa Lackey: "We were very grateful when NWS detected a fire south of Bouse Junction and was able to route forestry planes to the location...to assist in fire suppression. Our resources were spread thin already fighting fires across the county. The extra help in the fire detection and suppression really saved us. Firefighters were able to contain the fire before the wind [shift] later that evening." Throughout the remainder of the 2016 fire season, which generally occurs late winter to early spring on the southern Great Plains (Lindley et al. 2011), SRSOR and/or RSO were used in concert with the AWIPS tool to transmit 58 wildfire notifications. A total of $45(78 \%)$ notifications represented initial reports at ODEM and "many were received prior to emergency 911 calls" (D. Piltz 2016, personal communication).

Incorporating the use of high temporal resolution satellite data in wildland fire detection demonstrates a 


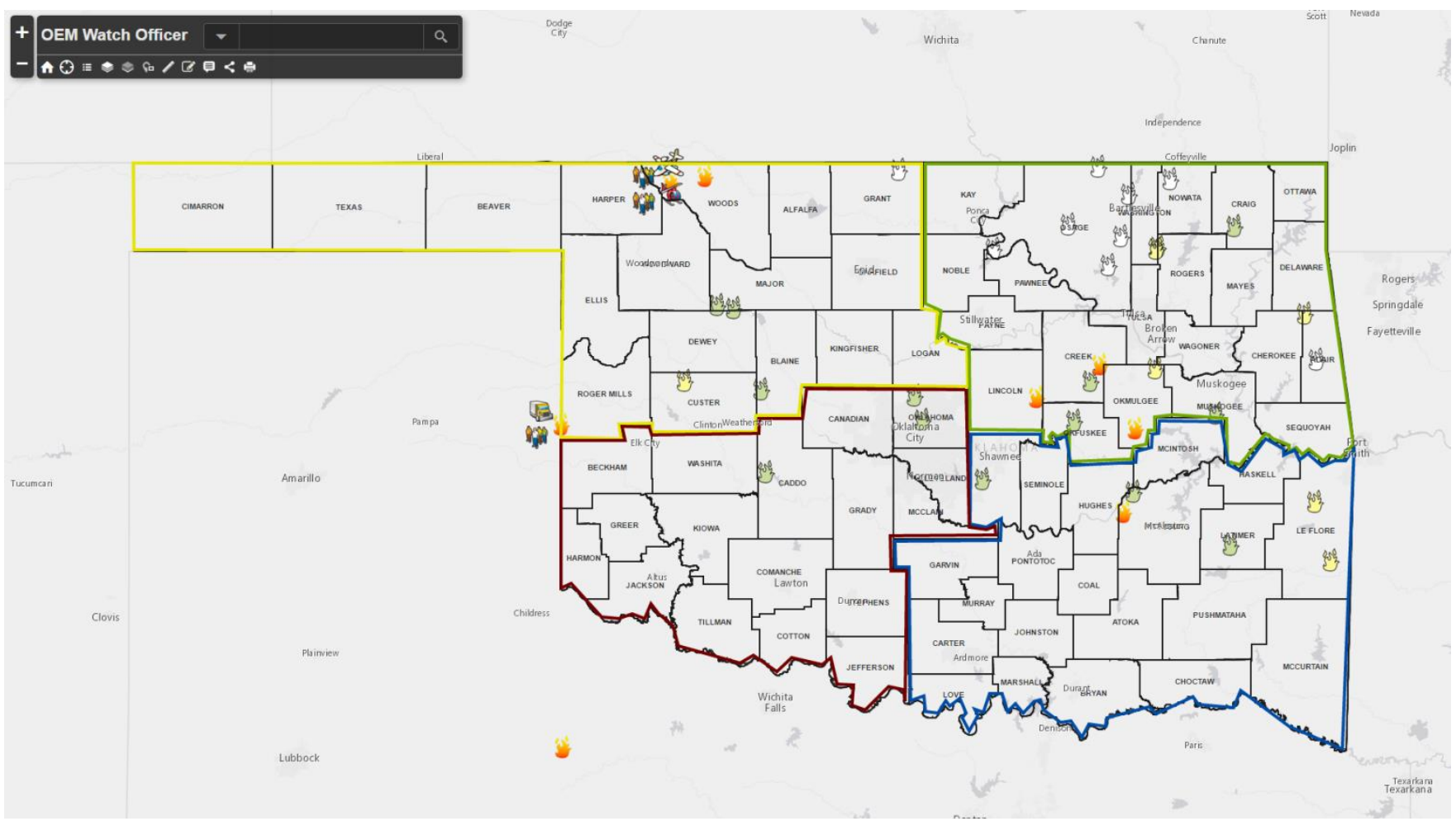

Figure 8. GIS-based online situational awareness display developed by ODEM in an effort to consolidate NWS and Oklahoma state agency inputs for wildland firefighting operations.

tactical role of meteorologists in firefighting operations. Historically, information provided by meteorologists in the management of wildland fire has been strategic in nature and focused on identifying impacts of future weather on the fire environment for planning and resource allocation. Operational meteorologists, however, have a unique vantage through remote sensing and can be the first to detect and categorize the scale of wildand fire events, especially in the near simultaneous occurrence of multiple fires characteristic of wildfire outbreaks on the southern Great Plains (Lindley et al. 2014). As this study demonstrates, meteorologists will have greater ability to provide intelligence about the location of emerging wildland fires and the character of fire propagation and intensity to fire officials with the use of high temporal imagery in the GOES-R era. Similar tactical involvement of fire meteorologists has been advocated through use of Doppler radar surveillance of the near-fire environment following the 2011 Bastrop Complex Wildfire in Texas (Murdoch et al. 2016). These remote sensing tools - and those yet to be realized in the GOES-R era and beyond-such as the fire detection and characterization algorithm (Schmidt 2014), greatly increase the capabilities and role of fire meteorologists toward tactical IDSS in firefighting operations.
Acknowledgments. The authors thank Mark Goeller and Drew Daily of the Oklahoma Forestry Services, Daniel Piltz of the Oklahoma Department of Emergency Management, Gregory Murdoch of the National Weather Service in Midland, Texas, Brad Smith of the Texas A\&M Forest Service, Timothy Schmit of NOAA/NESDIS/Center for Satellite Applications and Research/Advanced Satellite Products Branch in Madison, Wisconsin, as well as J.J. Brost and Gregory Patrick of the National Weather Service Southern Region Headquarters in Fort Worth, Texas.

\section{REFERENCES}

Cheney, P., and A. Sullivan, 2008: Grassfires: Fuel, Weather and Fire Behaviour. CSIRO Publishing, 150 pp.

Gravelle, C. M., K. J. Runk, K. L. Crandall, and D. W. Snyder, 2016: Forecaster evaluations of high temporal satellite imagery for the GOES-R era at the NWS Operations Proving Ground. Wea. Forecasting, 31, 1157-1177, Crossref.

Lindley, T. T., J. D. Vitale, W. S. Burgett, and M.-J. Beierle, 2011: Proximity meteorological observations for wind-driven grassland wildfire starts on the southern High Plains. Electronic J. Severe Storms Meteor., 6 (1), 1-27, [Available online at www.ejssm.org/ojs/index.php/ejssm/article/view/67/61.] 
, and Coauthors, 2014: Southern Great Plains wildfire outbreaks. Electronic J. Severe Storms Meteor., 9 (2), 1-43. [Available online at www.ejssm.org/ojs/ index.php/ejssm/article/view/132/98.]

Line, W. E., and K. Calhoun, 2014: GOES-R Proving Ground demonstration at the Hazardous Weather Testbed 2014 Spring Experiment final evaluation. NOAA/Hazardous Weather Testbed Rep., 36 pp. [Available online at www.goes-r.gov/users/docs/pgactivities/PGFR-HWT-2014-Final.pdf.]

, T. J. Schmit, D. T. Lindsey, and S. J. Goodman, 2016: Use of Geostationary Super Rapid Scan satellite imagery by the Storm Prediction Center. Wea. Forecasting, 31, 483-494, Crossref.

Menzel, W. P., and E. M. Prins, 1996: Monitoring biomass burning with the new generation of geostationary satellites. Biomass Burning and Global Change. J. S. Levine, Ed., MIT Press, 56-64.

Murdoch, G. P., R. R. Barnes, C. M. Gitro, T. T. Lindley, and J. D. Vitale, 2012: Assessing critical fire weather conditions using a red flag threat index. Electronic $J$. Operational Meteor., 13 (4), 46-56. [Available online at nwafiles.nwas.org/ej/pdf/2012-EJ4.pdf.]

, T. T. Lindley, and C. J. Morris 2016: A Doppler radar and conceptual analysis of horizontal longitudinal vortex influencing the Bastrop Complex wildfire. $J$. Operational Meteor., 4 (12), 160-169, Crossref.

NOAA, 2013: National Weather Service Weather-Ready Nation Roadmap, version 2.0. [Available online at www.nws.noaa.gov/com/weatherreadynation/files/nws wrn_roadmap_final_april17.pdf.]

Peterson, D. A., E. J. Hyer, J. R. Campbell, M. D. Fromm, J. W. Hair, C. F. Butler, and M. A. Fenn, 2015: The 2013 Rim Fire: Implications for predicting extreme fire spread, pyroconvection, and smoke emissions. Bull. Amer. Meteor. Soc., 96, 229-247, Crossref.

Ruminski, M. G., J. Simko, J. Kibler, D. McNamara, and T. Kasheta, 2003: The Hazard Mapping System (HMS) a multiplatform remote sensing approach to fire and smoke detection. Second International Wildland Fire Ecology and Fire Management Congress and Fifth Symposium on Fire and Forest Meteorology, 16-20 November 2003, Orlando, FL. American Meteorological Society, Boston, MA., 129-130. [Available online at ams.confex.com/ams/FIRE2003/ techprogram/paper_66607.htm.]

Schmidt, C., 2014: GOES-R land products: Fire detection and characterization. GOES-R (Geostationary Operational Environmental Satellite-R Series). [Available online at www.goes-r.gov/education/docs/ Factsheet_FireDetection_Feb2014.pdf]

Schmit, T. J., M. M. Gunshor, W. P. Menzel, J. J. Gurka, J. $\mathrm{Li}$, and A. S. Bachmeier, and, 2005: Introducing the next-generation Advanced Baseline Imager (ABI) on GOES-R. Bull. Amer. Meteor. Soc., 86, 1079-1096, Crossref.

, and Coauthors, 2013: Geostationary Operational Environmental Satellite (GOES)-14 super rapid scan operations to prepare for GOES-R. J. Appl. Remote Sens., 7, 073462, Crossref. , and __, 2015: Rapid Refresh information of significant events: Preparing users for the next generation of geostationary operational satellites. Bull. Amer. Meteor. Soc., 96, 561-576, Crossref.

, P. Griffith, M. Gunshor, J. Daniels, S. Goodman, and W. Lebair, 2016: A closer look at the ABI on the GOES-R Series. Bull. Amer. Meteor. Soc., in press, Crossref. 